\title{
A Survey of Extended-Interval Aminoglycoside Dosing Practices in United States Adult Cystic Fibrosis Programs
}

\author{
William A Prescott Jr PharmD
}

\begin{abstract}
INTRODUCTION: The Cystic Fibrosis Foundation recently deemed the use of extended-interval dosing (EID) of aminoglycosides acceptable for the treatment of cystic fibrosis (CF) pulmonary exacerbations. However, current practice across United States adult CF programs and affiliate programs is unknown. The objectives of this research are to characterize the practice trends, dosing strategies, therapeutic drug-monitoring practices, and adverse effect monitoring of the EID of aminoglycosides in the treatment of pulmonary exacerbations across United States adult CF programs. METHODS: A 34-question online survey instrument was distributed on behalf of the author by the United States Cystic Fibrosis Foundation to all United States adult CF programs and affiliate programs. RESULTS: Of the 68 participating adult CF programs (44.4\% survey response rate), 64 (94.1\%) reported using EID of aminoglycosides (as once-daily or twice-daily dosing). More than 95\% of programs reported frequently or always using this dosing method. Tobramycin dosed $10 \mathrm{mg} / \mathrm{kg} / \mathrm{d}$ every $24 \mathrm{~h}$, infused over 30-60 min, was the most commonly cited regimen. Monitoring of aminoglycoside serum concentrations was reported by all programs, with a tobramycin peak of $25-30 \mathrm{mg} / \mathrm{L}$ and trough of $<1 \mathrm{mg} / \mathrm{L}$ targeted most frequently. Nephrotoxicity was commonly monitored through serum creatinine measurements, while ototoxicity was monitored by audiometry in approximately one-half of programs. CONCLUSIONS: This study indicates that the use of EID of aminoglycosides across United States adult CF programs has increased considerably since the publication of the CF pulmonary exacerbation guidelines and now appears to be the most common method for dosing aminoglycosides in adults with CF. Key words: cystic fibrosis; aminoglycoside; extended-interval dosing. [Respir Care 2014;59(9):1353-1359. (C) 2014 Daedalus Enterprises]
\end{abstract}

\section{Introduction}

Extended interval dosing (EID) of aminoglycosides, which traditionally combines the total daily dose into a single dose that is administered once daily, has been critically evaluated in the adult population. ${ }^{1}$ Its use within health-care institutions across the United States increased from $19 \%$ in 1993 to $75 \%$ in 1998 , with $99.5 \%$ of institutions reporting the use of EID in persons 19-65 years of

\footnotetext{
Dr Prescott is affiliated with the University at Buffalo School of Pharmacy and Pharmaceutical Sciences, Buffalo, New York.

The author has disclosed no conflicts of interest.

Correspondence: William A Prescott Jr PharmD, University at Buffalo School of Pharmacy and Pharmaceutical Sciences, 218 Kapoor Hall, Buffalo, NY. E-mail: prescott@buffalo.edu.
}

DOI: $10.4187 /$ respcare. 02980 age. ${ }^{2,3}$ Compared with the general adult population, reports indicate the use of EID in patients with cystic fibrosis $(\mathrm{CF})$ to be less common. ${ }^{3-8}$ In the United States, $61 \%$ of pediatric/pediatric-adult $\mathrm{CF}$ accredited care centers and affiliate programs were using once-daily dosing of tobramycin as of January $2008 .{ }^{8}$ In light of the emergence of safety and efficacy data in the CF population, the Cystic Fibrosis Foundation deemed once-daily aminoglycoside dosing as acceptable for Pseudomonas aeruginosa (grade C recommendation) in its September 2009 pulmonary exacerbation guidelines. ${ }^{9-18}$ A 2009 survey of United States pediatric CF centers and affiliate programs distributed after the publication of these guidelines reported the use of EID (with once-daily or twice-daily dosing) in the pediatric CF population to be $94 \%$, a significant increase from previous reports. ${ }^{19}$ While empiric evidence suggests the use of EID of aminoglycosides to be increasingly common in the United States CF population, the prevalence of EID use across United States adult CF centers as well as the 
dosing and monitoring practices associated with this regimen following publication of the CF pulmonary exacerbation guidelines remain to be elicited.

The aim of this study is to characterize the practice trends, dosing strategies, therapeutic drug-monitoring practices, and adverse effect monitoring of EID (once-daily and twice-daily dosing) of aminoglycosides in the treatment of pulmonary exacerbations across United States adult CF programs. To do so, a survey instrument pertaining to the use of EID in persons with CF was distributed in cooperation with the Cystic Fibrosis Foundation to all United States CF accredited care centers and affiliate programs.

\section{Methods}

\section{Questionnaire}

The methods of this study have been previously outlined. ${ }^{19}$ The full survey instrument, which was distributed by the United States Cystic Fibrosis Foundation to pediatric and adult $\mathrm{CF}$ programs and affiliate programs in the United States, consisted of 52 multiple-choice and shortanswer questions. Skip logic was used so that adult CF programs did not need to answer questions pertaining to pediatrics, and vice versa. The survey instrument that pertained specifically to the adult CF population consisted of 38 questions regarding the demographics of the adult $\mathrm{CF}$ program and the use of EID in patients with $\mathrm{CF}$ at that program; the clarity of question composition was validated by a pulmonologist with experience using EID in the treatment of pulmonary exacerbations associated with CF. If the CF program used EID, questions were asked regarding which aminoglycosides are used, the dose and dosing interval used, the methods of administration, the methods for therapeutic drug monitoring, target serum concentrations, and the methods of monitoring for toxicity. The survey instrument tool was approved by the Social and Behavioral Sciences Institutional Review Board at the University at Buffalo on December 2, 2009.

\section{Data Collection}

All adult CF and affiliate programs in the United States were eligible for inclusion. Using the Cystic Fibrosis Foundation database, $263 \mathrm{CF}$ programs (110 pediatric, 96 adult, and 57 affiliate) were identified (via personal communication with the United States Cystic Fibrosis Foundation). Pediatric and adult CF programs located at the same site were considered to be distinct programs for the purpose of this study. Although the survey instrument was sent to both pediatric and adult $\mathrm{CF}$ accredited care centers and affiliate programs, the current publication only presents data from adult $\mathrm{CF}$ programs and those affiliate programs

\section{QUICK LOOK}

\section{Current knowledge}

The Cystic Fibrosis Foundation recently endorsed the use of extended-interval dosing of aminoglycosides acceptable for the treatment of pulmonary exacerbations of cystic fibrosis. The current practice of aminoglycoside use in United States adult cystic fibrosis programs is unknown.

\section{What this paper contributes to our knowledge}

The use of extended-interval dosing of aminoglycosides is commonplace in adult cystic fibrosis programs in the United States. This regimen has increased considerably across the United States since the publication of the cystic fibrosis pulmonary exacerbation guidelines and appears to be the most common method for dosing aminoglycosides in adults.

that indicated they provide care to the adult CF population (pediatric data previously published). ${ }^{19}$

The Cystic Fibrosis Foundation distributed an electronic hyperlink to the survey instrument to all medical directors and clinical coordinators at CF programs in the United States on December 17, 2009. Although the survey instrument was directed to CF center medical directors and clinical coordinators, the responsibility for completing the survey instrument could be delegated to a knowledgeable representative (eg, a CF center physician, $\mathrm{CF}$ center nurse or nurse practitioner, $\mathrm{CF}$ center physician assistant, or $\mathrm{CF}$ center pharmacist). To optimize the survey response rate, a reminder e-mail was distributed by the Cystic Fibrosis Foundation on February 4, 2010. The survey instrument remained open for 3 months and was closed on March 17, 2010. Survey-Monkey (Portland, Oregon) was used to distribute, collect, and analyze survey responses.

\section{Data Analysis}

Survey responses were numerically coded and entered into the computer database. To generalize the results, the response rate and distribution of responses were determined. Demographic data were grouped into 9 divisions based on geographic location, as defined by the United States Bureau of the Census (http://www.census.gov/geo/ maps-data/maps/pdfs/reference/us_regdiv.pdf). Frequency and other descriptive statistics were used to characterize the population and survey responses. The practice trends of EID used in the treatment of CF pulmonary exacerbations across adult CF programs in the United States was characterized using $95 \%$ CIs. 


\section{Extended-Interval Dosing in Adult Cystic Fibrosis}

Table 1. Demographics of Cystic Fibrosis Foundation-Accredited Adult Care Centers and Affiliate Programs

\begin{tabular}{|c|c|}
\hline $\begin{array}{l}\text { Region } \\
(n=68)\end{array}$ & $\begin{array}{c}\text { Centers Participating in Survey, } \\
n \text { (\% Responding Programs) }\end{array}$ \\
\hline New England* & $5(7.4)$ \\
\hline Middle Atlantic $\dagger$ & $16(23.5)$ \\
\hline South Atlantic $\ddagger$ & $13(19.1)$ \\
\hline East North§ & $12(17.6)$ \\
\hline East South\| & $2(2.9)$ \\
\hline West North $\rrbracket$ & $6(8.8)$ \\
\hline West South\# & $3(4.4)$ \\
\hline Mountain** & $3(4.4)$ \\
\hline Pacific $\dagger \dagger$ & $8(11.8)$ \\
\hline \multicolumn{2}{|c|}{$\begin{array}{l}\text { Demographic data were grouped into nine divisions based on geographic location as defined } \\
\text { by the United States Bureau of the Census (http://www.census.gov/geo/maps-data/maps/pdfs/ } \\
\text { reference/us_regdiv.pdf). } \\
\text { * Connecticut }(n=1) \text {, Maine }(n=1) \text {, Massachusetts }(n=2) \text {, New Hampshire }(n=0) \text {, } \\
\text { Rhode Island }(n=0) \text {, and Vermont }(n=1) \text {. } \\
\dagger \text { New Jersey }(n=3) \text {, New York }(n=8) \text {, and Pennsylvania }(n=5) \text {. } \\
\text { ‡ Delaware }(n=0) \text {, Washington, DC }(n=1) \text {, Florida }(n=7) \text {, Georgia }(n=1) \text {, Maryland } \\
(n=1) \text {, North Carolina }(n=0) \text {, South Carolina }(n=0) \text {, Virginia }(n=2) \text {, and West } \\
\text { Virginia }(n=1) \text {. } \\
\S \text { Illinois }(n=2) \text {, Indiana }(n=1) \text {, Michigan }(n=4) \text {, Ohio }(n=3) \text {, and Wisconsin }(n=2) \text {. } \\
\| \text { Alabama }(n=1) \text {, Kentucky }(n=0) \text {, Mississippi }(n=0) \text {, and Tennessee }(n=1) \text {. } \\
\text { II Iowa }(n=2) \text { Kansas }(n=0) \text {, Minnesota }(n=1) \text {, Missouri }(n=1) \text {, Nebraska }(n=1) \text {, } \\
\text { North Dakota }(n=0) \text {, and South Dakota }(n=1) \text {. } \\
\text { \# Arkansas }(n=0) \text {, Louisiana }(n=2) \text {, Oklahoma }(n=0) \text {, and Texas }(n=1) \text {. } \\
\text { ** Arizona }(n=0) \text {, Colorado }(n=1) \text {, Idaho }(n=1) \text {, Montana }(n=0) \text {, New Mexico } \\
(n=0) \text {, Utah }(n=0) \text {, Nevada }(n=1) \text {, and Wyoming }(n=0) \text {. } \\
\dagger \dagger \text { Alaska }(n=1) \text {, California }(n=4) \text { Hawaii }(n=1) \text {, Oregon }(n=1) \text {, and Washington } \\
(n=1) \text {. }\end{array}$} \\
\hline
\end{tabular}

\section{Results}

\section{Demographic Characteristics}

Responses were received from 68 adult $\mathrm{CF}$ programs, representing a survey response rate of $44.4 \%$. The New England, Middle Atlantic, South Atlantic, East North, and East South regions accounted for $70.6 \%$ of responding programs, while the West North, West South, Mountain, and Pacific regions accounted for $29.4 \%$ of responding programs (Table 1), which is similar to the geographic distribution of programs across the United States of $\sim 65 \%$ and $35 \%$, respectively. The survey response rates within the aforementioned regions was $51.1 \%$ and $37.7 \%$, respectively, with the highest survey response obtained from the Middle Atlantic region (80\%) and the lowest survey response obtained from the West South region $(21.4 \%)$. The survey instrument was completed by $49 \mathrm{CF}$ center medical directors $(64.5 \%), 7$ clinical coordinators $(9.2 \%), 4 \mathrm{CF}$ center physicians $(5.3 \%), 5 \mathrm{CF}$ center nurse or nurse practitioners $(6.6 \%)$, and $11 \mathrm{CF}$ center pharmacists $(14.5 \%)$. Multiple responses were received from 7 programs: $\mathrm{CF}$ center medical director and nurse/nurse practitioner $(n=2)$; $\mathrm{CF}$ center medical director and CF center pharmacist $(n=2)$; CF center medical director and clinical coordi- nator $(n=1)$; CF center physician, CF center pharmacist and clinical coordinator $(n=1)$; and CF center pharmacist and clinical coordinator $(n=1)$. In these instances, responses were combined.

\section{EID Use in Adult CF}

Sixty-four of the 68 participating adult $\mathrm{CF}$ programs (94.1\%, 95\% CI 89.9-98.3\%) reported the use of EID (as once-daily or twice-daily dosing). The frequency of use was classified as rare by $2(3.1 \%)$, occasional by one (1.6\%), frequent by $30(46.9 \%)$, and always by 31 (48.4\%) adult $\mathrm{CF}$ programs. The most commonly used aminoglycoside was tobramycin $(98.4 \%)$, followed by amikacin $(34.4 \%)$ and gentamicin $(20.3 \%)$. One program reported using tobramycin and not using amikacin, but did not indicate whether they did or did not use gentamicin, and was therefore assumed to not use the latter aminoglycoside.

\section{EID Dosing in CF}

Among patients naive to an aminoglycoside (eg, patients who had not been treated previously and in whom the dose could not be individualized based on previous therapeutic drug monitoring), an empiric dose of $10 \mathrm{mg} /$ $\mathrm{kg} / \mathrm{d}$ tobramycin and gentamicin were used most commonly (Table 2). Amikacin dosing was quite variable, ranging from 15 to $40 \mathrm{mg} / \mathrm{kg} / \mathrm{d}$. Among patients treated with an aminoglycoside previously and in whom the dose could be based on prior therapeutic drug monitoring, 21 of 63 adult CF programs $(33.3 \%)$ individualized dosing in patients receiving tobramycin, 7 of $21(33.3 \%)$ in patients receiving amikacin, and 4 of $13(30.8 \%)$ in patients receiving gentamicin.

An interval of $24 \mathrm{~h}$ was identified as the most common regimen by $93.8 \%$ adult CF programs (Table 2); of the 64 adult CF programs using EID, 61 (95.3\%, 95\% CI 91.6$99.1 \%$ ) reported the use of once-daily EID and $53(82.8 \%$, 95\% CI 75.7-89.9\%) reported exclusive use of once-daily EID. In contrast, an EID interval of $12 \mathrm{~h}$ was used by 9 (14.1\%, 95\% CI 7.9-20.3\%) adult CF programs with only one $(1.6 \%, 95 \%$ CI $0-3.8 \%)$ program exclusively using this interval. Regardless of dose, an infusion time of 30 or 60 min was reported by 50 of $64(78.1 \%)$ adult CF programs (Table 2).

\section{Therapeutic Drug Monitoring of EID in CF}

Therapeutic drug monitoring of aminoglycoside serum concentrations for patients receiving EID was reported by $100 \%$ of adult CF programs. The methods of doing so, which were reported by 63 programs, varied considerably (Table 3). Obtaining 2 random aminoglycoside serum concentrations was the most frequently reported method. The 


\section{Extended-Interval Dosing in Adult Cystic Fibrosis}

Table 2. Dosing of Extended-Interval Aminoglycosides Across Cystic Fibrosis Foundation Accredited Adult Care Centers and Affiliate Programs

\begin{tabular}{|c|c|}
\hline Doses & Centers, $n(\%)$ \\
\hline \multicolumn{2}{|c|}{ Tobramycin empiric dose $(n=63)$} \\
\hline $10 \mathrm{mg} / \mathrm{kg} / \mathrm{d}$ & $53(84.1)$ \\
\hline Other* & $10(15.9)$ \\
\hline \multicolumn{2}{|c|}{ Amikacin empiric dose $(n=22)$} \\
\hline $30 \mathrm{mg} / \mathrm{kg} / \mathrm{d}$ & $11(50.0)$ \\
\hline Other $\dagger$ & $11(50.0)$ \\
\hline \multicolumn{2}{|c|}{ Gentamicin empiric dose $(n=13)$} \\
\hline $10 \mathrm{mg} / \mathrm{kg} / \mathrm{d}$ & $10(76.9)$ \\
\hline Other $\ddagger$ & $3(23.1)$ \\
\hline \multicolumn{2}{|c|}{ Most common dosing interval used $(n=64)$} \\
\hline Q12 h & $1(1.6)$ \\
\hline Q24 h & $60(93.8)$ \\
\hline Q12 and Q24 h equally & $2(3.1)$ \\
\hline Other§ & $1(1.6)$ \\
\hline \multicolumn{2}{|l|}{ Infusion time $(\min )(n=64)$} \\
\hline$<15$ & $1(1.6)$ \\
\hline 15 & $2(3.1)$ \\
\hline 30 & $26(40.6)$ \\
\hline 45 & $2(3.1)$ \\
\hline 60 & $24(37.5)$ \\
\hline Other\| & $9(14.1)$ \\
\hline \multicolumn{2}{|c|}{$\begin{array}{l}\text { * Other tobramycin doses: } 7.5-10 \mathrm{mg} / \mathrm{kg} / \mathrm{d}(n=1) ; 8 \mathrm{mg} / \mathrm{kg} / \mathrm{d}(n=1) ; 10 \mathrm{mg} / \mathrm{kg} / \mathrm{d} \text { if patient } \\
\text { was }<50 \text { years of age and } 8 \mathrm{mg} / \mathrm{kg} / \mathrm{d} \text { if patient was } \geq 50 \text { years of age }(n=1) ; 10 \mathrm{mg} / \mathrm{kg} \\
\text { every } 16 \mathrm{~h}(n=1) ; 10-12 \mathrm{mg} / \mathrm{kg} / \mathrm{d}(n=2) ; 14 \mathrm{mg} / \mathrm{kg} / \mathrm{d}(n=1) ; \text { and unspecified }(n=3) \text {. } \\
\dagger \text { Other amikacin doses: } 15 \mathrm{mg} / \mathrm{kg} / \mathrm{d}(n=2) ; 15-22.5 \mathrm{mg} / \mathrm{kg} / \mathrm{d}(n=1) ; 15-25 \mathrm{mg} / \mathrm{kg} / \mathrm{d} \\
(n=1) ; 20 \mathrm{mg} / \mathrm{kg} / \mathrm{d}(n=2) ; 20-25 \mathrm{mg} / \mathrm{kg} / \mathrm{d}(n=1) ; 20-30 \mathrm{mg} / \mathrm{kg} / \mathrm{d}(n=2) ; 30 \mathrm{mg} / \mathrm{kg} / \mathrm{d} \text { if } \\
\text { patient was }<50 \text { years of age and } 24 \mathrm{mg} / \mathrm{kg} / \mathrm{d} \text { if patient was } \geq 50 \text { years of age }(n=1) ; \text { and } \\
40 \mathrm{mg} / \mathrm{kg} / \mathrm{d}(n=1)\end{array}$} \\
\hline
\end{tabular}

most frequent target serum concentrations (for tobramycin or gentamicin) were a measured/calculated peak of 25 $30 \mathrm{mg} / \mathrm{L}$ and a measured/calculated trough of $<1 \mathrm{mg} / \mathrm{L}$. The area under the curve was infrequently used for therapeutic drug monitoring (see Table 3). A dosing nomogram was used to guide therapeutic drug monitoring at 15 of 62 responding adult CF programs (24.2\%). Nomogram details were specified by only 3 programs; the "Hartford nomogram" was cited twice, and an unspecified published nomogram was cited once. Aminoglycoside serum concentrations were repeated by 55 of 63 adult CF programs $(87.3 \%)$, with monitoring occurring every other day at one program (1.8\%), every 3 days at 3 programs (5.5\%), every 7 days at 23 programs (41.8\%), and every 14 days at 1 program (1.8\%). Ten programs (18.2\%) reported follow-up monitoring on an as-needed basis using clinical judgment, 4 programs (7.3\%) reported monitoring levels every $7 \mathrm{~d}$ or
Table 3. Therapeutic Drug Monitoring Practices With ExtendedInterval Aminoglycoside Dosing Across Cystic Fibrosis Foundation-Accredited Adult Care Centers and Affiliate Programs

\begin{tabular}{|c|c|}
\hline Variables & Centers, $n(\%)$ \\
\hline \multicolumn{2}{|l|}{ Serum concentrations collected $(n=63)$} \\
\hline Peak & $1(1.6)$ \\
\hline Trough & $12(19.1)$ \\
\hline Peak and trough & $15(23.8)$ \\
\hline Single random level & $10(15.9)$ \\
\hline 2 random levels & $23(36.5)$ \\
\hline Other* & $2(3.2)$ \\
\hline \multicolumn{2}{|l|}{ Goal peak $(\mathrm{mg} / \mathrm{L})(n=38) \dagger+$} \\
\hline$<15$ & $2(5.3)$ \\
\hline $15-20$ & $2(5.3)$ \\
\hline $20-25$ & $5(13.2)$ \\
\hline $25-30$ & $13(34.2)$ \\
\hline $30-35$ & $3(7.9)$ \\
\hline$>35$ & $2(5.3)$ \\
\hline Other§ & $11(29.0)$ \\
\hline \multicolumn{2}{|l|}{ Goal trough $(\mathrm{mg} / \mathrm{L})(n=50) \dagger \|$} \\
\hline$<0.1$ & $6(12.0)$ \\
\hline$\leq 0.1$ & $6(12.0)$ \\
\hline$<1$ & $20(40.0)$ \\
\hline$\leq 1$ & $8(16.0)$ \\
\hline OtherdI & $10(20.0)$ \\
\hline \multicolumn{2}{|l|}{ Goal AUC $(\mathrm{mg} * \mathrm{~h} / \mathrm{L})(n=11) \dagger$} \\
\hline 100 & $10(90.9)$ \\
\hline Other\# & $1(9.1)$ \\
\hline \multicolumn{2}{|c|}{$\begin{array}{l}\text { * Other serum concentrations collected; peak and two random serum concentrations }(n=1) \text {, } \\
\text { and 2-, 6-, and 12-h serum concentrations }(n=1) \text {. } \\
\text { † Goal serum concentrations are specific to tobramycin or gentamicin. } \\
\text { \$ Measured or extrapolated (calculated) peak occurring } 60 \text { min post start of infusion } \\
\text { \$ Other targeted peak serum concentrations: } 15-30 \mathrm{mg} / \mathrm{L}(n=1) ; 20-30 \mathrm{mg} / \mathrm{L}(n=5) ; 20- \\
35 \mathrm{mg} / \mathrm{L}(n=1) ; 20-40 \mathrm{mg} / \mathrm{L}(n=1) ; 25-35 \mathrm{mg} / \mathrm{L}(n=2) \text {; and } 25-40 \mathrm{mg} / \mathrm{L}(n=1) \text {. } \\
\| \text { Measured or extrapolated (calculated) trough occurring at the end of the dosing interval (eg, } \\
24 \text { h postdose with Q24 h dosing). } \\
\text { TI Other targeted trough serum concentrations: }<0.2(n=2) ;<0.3 \mathrm{mg} / \mathrm{L}(n=1) ;<0.5 \mathrm{mg} / \\
\mathrm{L}(n=3) ; \leq 0.5 \mathrm{mg} / \mathrm{L}(n=1) ;<1-2 \mathrm{mg} / \mathrm{L}(n=1) ;<2 \mathrm{mg} / \mathrm{L}(n=1) \text {; and undetectable } \\
\text { for } 6 \mathrm{~h}(n=1) \text {. } \\
\text { \# Other targeted AUC values: } 75-150 \mathrm{mg} \cdot \mathrm{h} / \mathrm{L}(n=1) \text {. } \\
\text { AUC = Area under the concentration-time curve }\end{array}$} \\
\hline
\end{tabular}

per clinical judgment, and 13 programs (23.6\%) reported using some other method.

\section{Safety-Monitoring Parameters With EID in CF}

Of the 63 programs who specified their method of monitoring for nephrotoxicity, serum creatinine level was followed as a marker of renal function in 62 of 63 adult $\mathrm{CF}$ programs $(98.4 \%)$, while serum electrolyte levels, urine output, and urinalysis were monitored by 24 of 63 (38.1\%), 19 of $63(30.2 \%)$, and 15 of $63(23.8 \%)$ programs, respectively. Among adult CF programs measuring serum creatinine level, all programs reported further follow-up of this laboratory parameter: 9 of 62 (14.5\%), 29 of 62 (46.8\%), 


\section{Extended-Interval Dosing in Adult Cystic Fibrosis}

and 2 of $62(3.2 \%)$ programs indicated monitoring this parameter every 3,7 , and 14 days, respectively, while 9 of 62 programs (14.5\%) reported that subsequent monitoring of serum creatinine levels was based on clinical judgment alone. All adult CF programs monitored patients for ototoxicity, with 28 of 62 programs (45.2\%) using audiometry. Specifically, 25 of $62(40.3 \%)$ and 20 of 62 (32.3\%) programs reported using high- and low-frequency audiometry, respectively, while 8 of 62 programs $(12.9 \%)$ reported monitoring for vestibular toxicity. The frequency of monitoring audiometry and timing in relation to antibiotic treatment varied greatly across programs, although $\sim 40 \%$ of programs conducted low- and/or high-frequency audiometry annually.

\section{Discussion}

The current survey of aminoglycoside EID practices across adult CF programs in the United States serves as a follow-up study to the state-of-the-art survey conducted by Van Meter et al in 2007-2008. ${ }^{8}$ This follow-up survey indicates that the vast majority of adult CF programs (94\%) now use EID (as once-daily or twice-daily dosing) in the treatment of pulmonary exacerbations, with $83 \%$ of adult CF programs using once-daily EID exclusively. That noted, the percentage of adult CF programs reporting the use of once-daily EID may better reflect current EID practices because a twice-daily dosing approach may not have been considered to be EID by all respondents. This study is the first to investigate the use of this regimen specifically in the adult CF population, and is the first to assess EID practices (both once-daily and twice-daily dosing) with tobramycin, gentamicin, and amikacin in those with CF. Because the current study was conducted after the publication of the Cystic Fibrosis Foundation pulmonary exacerbation guidelines, it should provide an accurate reflection of current practices of EID across United States adult CF programs.

Comparing these data with United States adult/pediatric CF program data collected from November 2007 to January 2008 indicates that the use of EID (dosed once daily) has increased $\sim 20 \%$ since the release of the Cystic Fibrosis Foundation pulmonary exacerbation guidelines. ${ }^{8}$ Further comparing these data with pediatric CF program data collected as part of this study (following the release of the Cystic Fibrosis Foundation pulmonary exacerbation guidelines) indicates that the use of EID is essentially the same in pediatric and adult $\mathrm{CF}$ programs across the United States. ${ }^{19}$ That said, the overall use of this regimen in the adult $\mathrm{CF}$ population is likely more common because the use of EID in pediatric CF varies based on age with its use being most common in adolescents and least common in younger pediatric patients, and because a higher percentage of adult CF programs frequently or always use EID. ${ }^{19}$
Tobramycin is the most commonly used aminoglycoside for EID in adult patients with CF, while amikacin and gentamicin are used less frequently. This likely reflects the availability of well-designed safety and efficacy studies and meta-analyses evaluating tobramycin EID in this population, and the lack of published research studies assessing the use of gentamicin and amikacin EID in those with CF. ${ }^{10,11,13-18}$ As in the pediatric CF population, empiric dosing of tobramycin was most commonly prescribed at $10 \mathrm{mg} / \mathrm{kg} / \mathrm{d} .{ }^{19}$ This practice is consistent with the dose used in a large, randomized, controlled, noninferiority study published in 2005.14 However, many adult CF programs use therapeutic drug-monitoring data from previous hospital admissions to individualize the dose, which is similar to the practice that has been reported in pediatric CF programs. ${ }^{19}$ An interval of $24 \mathrm{~h}$ is used by the majority of $\mathrm{CF}$ programs and was identified as the most commonly used regimen. In contrast to practice in the pediatric CF population, in whom twice-daily EID is gaining favor among some clinicians, the use of twice-daily dosing is less common among adult $\mathrm{CF}$ programs. ${ }^{19}$

Therapeutic drug monitoring of aminoglycoside serum concentrations is common, which is expected given the narrow therapeutic index of this class of antibiotics. However, as is the case with pediatric CF programs, the methods of monitoring and the targeted serum concentrations associated with EID vary widely across United States adult CF programs. ${ }^{19}$ This survey indicates that adult CF programs most commonly obtain 2 random serum concentrations, with the first random concentration obtained at least $2 \mathrm{~h}$ post-dose. A tobramycin peak serum concentration of $25-30 \mathrm{mg} / \mathrm{L}$ and a trough value of $<1 \mathrm{mg} / \mathrm{L}$ were the most frequent targets. These goals were similar to those levels achieved in the Smyth et $\mathrm{al}^{14}$ study, although an extrapolated trough value of $\leq 0.1 \mathrm{mg} / \mathrm{L}$, used by approximately $25 \%$ of programs, may actually be a more appropriate trough target as it better reflects the mean trough value of $0.1 \mathrm{mg} / \mathrm{L}$ reported by Smyth et al. ${ }^{14}$ Furthermore, targeting a trough value of $\leq 0.1 \mathrm{mg} / \mathrm{L}$ (instead of $\leq 1 \mathrm{mg} / \mathrm{L}$ ) may minimize the risk of toxicity that may be associated with elevated areas under the curve over an extended treatment duration. This survey indicates a dosing nomogram is used to guide therapeutic drug monitoring in nearly $25 \%$ of adult CF programs. Although a oncedaily EID nomogram for tobramycin $12 \mathrm{mg} / \mathrm{kg} / \mathrm{d}$ has been validated in the pediatric $\mathrm{CF}$ population, ${ }^{20}$ a validated nomogram for use in adult patients with $\mathrm{CF}$ is lacking. Approximately two-thirds of adult $\mathrm{CF}$ programs repeat serum concentration measurements for follow-up, with most programs repeating the measurement of serum concentrations once weekly and/or based on clinical judgment. Onceweekly follow-up is appropriate to prevent the toxicities associated with exposure to an elevated tobramycin level over an extended duration of treatment. 


\section{Extended-Interval Dosing in Adult Cystic Fibrosis}

The risk of acute nephrotoxicity and ototoxicity with aminoglycoside therapy is well-known. The occurrence of these toxicities does not appear to differ significantly among patients with $\mathrm{CF}$ who are treated with once-daily EID and traditional dosing every 8 h. ${ }^{14,15}$ As is the case across United States pediatric CF programs, serum creatinine level was measured routinely in nearly all adult CF programs, with weekly assessment being the most common. ${ }^{19}$ However, one program did not monitor serum creatinine levels, a practice that may unnecessarily place patients at risk for toxicity. Monitoring for ototoxicity using diagnostic techniques such as audiometry and vestibular function testing is less common. Among adult CF programs monitoring for ototoxicity, the methods of doing so vary widely, the reasons for which are unclear.

Several limitations of the current study must be acknowledged. The response rate of $44.4 \%$ is below the commonly accepted threshold of $60 \%$, and nonresponse bias should therefore be considered when interpreting the results of this study. A second limitation is that while the survey instrument was validated by a pulmonologist with experience using EID in the treatment of CF pulmonary exacerbations, and the majority of survey responses were provided by the $\mathrm{CF}$ center medical director or a CF physician, the validation process did not include reviewers representative of all potential survey respondents (eg, $\mathrm{CF}$ center clinical coordinator, $\mathrm{CF}$ center nurse or nurse practitioner, $\mathrm{CF}$ center physician assistant, and CF center pharmacist). Questions might have been answered differently among different members at the same program based on their role in therapeutic drug monitoring and interpretation of the questions, potentially introducing bias in data reporting. A third limitation was the need to combine data from programs having more than one response. Although allowing multiple responses per program may have bolstered the survey response rate, there were some discrepant responses, most notably with center demographics. However, all responses pertaining to the primary objective of the study were congruent. A fourth limitation is that EID was not specifically defined in the survey instrument, which may have led to an interpretation that EID referred only to once-daily dosing, instead of to both once-daily and twice-daily dosing using the same daily doses (eg, $10 \mathrm{mg} / \mathrm{kg} / \mathrm{d}$ divided into one or 2 daily doses). Therefore, the latter may not have been considered to be EID by all respondents.

In conclusion, the use of EID aminoglycosides is commonplace among adult CF programs in the United States. The use of this regimen across the United States has increased considerably since the publication of the CF pulmonary exacerbation guidelines endorsing this regimen and now appears to be the most common method for dosing aminoglycosides in adults with CF. Tobramycin, dosed $10 \mathrm{mg} / \mathrm{kg} / \mathrm{d}$ every $24 \mathrm{~h}$, infused over $30-60 \mathrm{~min}$, is the most commonly used regimen. Monitoring this therapeutic regimen with 2 random serum concentrations targeting a measured/calculated peak of $25-30 \mathrm{mg} / \mathrm{L}$ and a measured/ calculated trough of $<1 \mathrm{mg} / \mathrm{L}$ is most common. Adult CF programs in the United States currently using EID should use these data to compare and contrast their practices to those of adult CF programs across the country, while those adult CF programs considering the use of EID should use these data for reference when implementing EID protocols at their institution. Future work should be done to standardize care with regard to EID of aminoglycosides and therapeutic monitoring across all United States CF programs.

\section{ACKNOWLEDGMENTS}

The author thanks Dr Bruce Marshall and his staff at the Cystic Fibrosis Foundation for distributing this survey to CF programs in the United States. The author also thanks Ms Michelle Khait for her contributions throughout this project, Dr Jack Sharp for his assistance in validating our survey tool, and Dr Alan Forrest for his assistance with statistical analysis.

\section{REFERENCES}

1. Barza M, Ioannidis JP, Cappelleri JC, Lau J. Single or multiple daily doses of aminoglycosides: a meta-analysis. BMJ 1996;312(7027): 338-345.

2. Chuck SK, Raber SR, Rodvold KA, Areff D. National survey of extended-interval aminoglycoside dosing. Clin Infect Dis 2000;30(3): 433-439.

3. Schumock GT, Raber SR, Crawford SY, Naderer OJ, Rodvold KA. National survey of once-daily dosing of aminoglycoside antibiotics. Pharmacotherapy 1995;15(2):201-209.

4. Phillips JA, Bell SC. Aminoglycosides in cystic fibrosis: a descriptive study of current practice in Australia. Intern Med J 2001;31(1): 23-26.

5. Tan KH, Hyman-Tylor P, Mulheran M, Knox A, Smyth A. Lack of concordance in the use and monitoring of intravenous aminoglycosides in UK cystic fibrosis centers. Pediatr Pulmonol 2002;33(2): 165.

6. Cheong J, Jacklin A, Hodson M. The influence of the TOPIC study on the prescribing guidelines of aminoglycosides in cystic fibrosis units. Pediatr Pulmonol 2008;43(S31):363.

7. Condren M, Luedtke SA. Prescribing patterns for extended interval aminoglycoside dosing in pediatric patients. J Pediatr Pharmacol Ther 2001;6:385-391.

8. Van Meter DJ, Corriveau M, Ahern JW, Lahiri T. A survey of once-daily dosage tobramycin therapy in patients with cystic fibrosis. Pediatr Pulmonol 2009;44(4):325-329.

9. Flume PA, Mogayzel PJ Jr, Robinson KA, Goss CH, Rosenblatt RL, Kuhn RJ, et al. Cystic fibrosis pulmonary guidelines: treatment of pulmonary exacerbations. Am J Respir Crit Care Med 2009;180(9): 802-808.

10. Burkhardt O, Lehmann C, Madabushi R, Kumar V, Derendorf H, Welte T. Once-daily tobramycin in cystic fibrosis: better for clinical outcome than thrice-daily tobramycin but more resistance development? J Antimicrob Chemother 2006;58(4):822-829.

11. Master V, Roberts GW, Coulthard KP, Baghurst PA, Martin A, Roberts ME, et al. Efficacy of once-daily tobramycin monotherapy for acute pulmonary exacerbations of cystic fibrosis: a preliminary study. Pediatr Pulmonol 2001;31(5):367-376. 


\section{Extended-Interval Dosing in Adult Cystic Fibrosis}

12. Powell SH, Thompson WL, Luthe MA, Stern RC, Grossniklaus DA, Bloxham DD, et al. Once-daily vs. continuous aminoglycoside dosing: efficacy and toxicity in animal and clinical studies of gentamicin, netilmicin, and tobramycin. J Infect Dis 1983;147(5):918-932.

13. Riethmueller J, Franke P, Schroeter TW, Claass A, Busch A, Ziebach $\mathrm{R}$, et al. Optimized intravenous antibiotic treatment with Ceftazidime (thrice daily vs. continuous) and tobramycin (thrice vs. once daily) in CF patients. Abstracts of the 24th European Cystic Fibrosis Conference, June 6-9, 2001, Vienna, Austria:P192.

14. Smyth A, Tan KH, Hyman-Taylor P, Mulheran M, Lewis S, Stableforth $\mathrm{D}$, et al. Once versus three-times daily regimens of tobramycin treatment for pulmonary exacerbations of cystic fibrosis- the TOPIC study: a randomised controlled trial. Lancet 2005;365(9459):573578

15. Smyth AR, Bhatt J. Once-daily versus multiple-daily dosing with intravenous aminoglycosides for cystic fibrosis. Cochrane Database Syst Rev 2010;(1):CD002009.
16. Vic P, Ategbo S, Turck D, Husson MO, Launay V, Loeuille GA, et al. Efficacy, tolerance, and pharmacokinetics of once daily tobramycin for pseudomonas exacerbations in cystic fibrosis. Arch Dis Child 1998;78(6):536-539.

17. Vic P, Ategbo S, Turck D, Husson MO, Tassin E, Loeuille GA, et al. Tolerance, pharmacokinetics and efficacy of once daily amikacin for treatment of Pseudomonas aeruginosa pulmonary exacerbations in cystic fibrosis patients. Eur J Pediatr 1996;155(11):948-953.

18. Whitehead A, Conway SP, Etherington C, Caldwell NA, Setchfield $\mathrm{N}$, Bogle S. Once-daily tobramycin in the treatment of adult patients with cystic fibrosis. Eur Respir J 2002;19(2):303-309.

19. Prescott WA. National Survey of Extended-Interval Aminoglycoside Dosing in Pediatric Cystic Fibrosis Pulmonary Exacerbations. J Pediatr Pharmacol Ther 2011;16(4):262-269.

20. Massie J, Cranswick N. Pharmacokinetic profile of once daily intravenous tobramycin in children with cystic fibrosis. J Paediatr Child Health 2006;42(10):601-605. 